\title{
Assistência de enfermagem ao paciente com grandes queimaduras em um hospital público no interior sul da Amazônia ocidental
}

\author{
Nursing care to patient with severe burn in a public hospital in south western Amazon
}

Atención de enfermería al pacientes con grandes quemaduras en un hospital público en el sur de Amazonia occidental

Poliana Deyse Pereira Gouvêa ${ }^{1 *}$, Angélica Inácio Da Cruz Oliveira², Tatiane Maestá2 ${ }^{2}$ Cássia de Oliveira Pinto Rosa², Emanoela Maria Rodrigues de Sousa², Paulo Henrik Silva Pinheiro².

\section{RESUMO}

Objetivo: Relatar o caso de uma paciente vítima de grande queimadura caracterizando a evolução das feridas, relatando sobre as coberturas utilizadas durante todo o tratamento e ressaltar a importância dos cuidados de enfermagem em conjunto com a equipe multiprofissional. Detalhamento do caso: $O$ caso trata-se de uma adolescente, vítima de queimaduras em um acidente envolvendo uma explosão ao acender uma churrasqueira com etanol, apresentou $49 \%$ da superfície corporal queimada, foi admitida no hospital onde foi realizado o tratamento juntamente com a equipe multidisciplinar e a realização dos curativos pelas enfermeiras residentes durante um período de 40 dias, com acompanhamento após alta. Considerações finais: Constatou uma escassez de estudos sobre o uso de coberturas em queimaduras, além de que, é preciso treinar a equipe multiprofissional, chamando uma atenção maior para os enfermeiros que estão na linha de frente, para oferecer suporte necessário aos pacientes queimados, deixando-os com o mínimo de sequelas mentais, sociais e físicas.

Palavras-chaves: Queimadura, Enfermagem, Cicatrização.

\begin{abstract}
Objective: To report the case of a patient with a severe burn, characterizing the evolution of the wounds, reporting on the coverage used throughout the treatment and highlighting the importance of nursing care in conjunction with the multiprofessional team. Case Detail / Experience Report: The case is about a teenage girl, burned victim in an accident involving an explosion when was a barbecue grill with ethanol, showed $49 \%$ of the burned body surface, she was admitted to the hospital where the treatment was carried out together with the multidisciplinary team and the dressing performed by the resident nurses over a period of 40 days, with follow-up after discharge. Conclusion: It found a scarcity of studies on the use of burn coverings, and it is necessary to train the multidisciplinary team, drawing greater attention to nurses who are in the front line, to provide necessary support to burned patients, leaving them with minimal mental, social and physical sequelae.
\end{abstract}

Keywords: Burn, Wound healing, Nursing.

\section{RESUMEN}

Objetivo: Informar el caso de un paciente con una quemadura grave, caracterizar la evolución de las heridas, informar sobre la cobertura utilizada durante todo el tratamiento y resaltar la importancia de la atención de enfermería en conjunto con el equipo multiprofesional. Detalle del caso / Informe de

${ }^{1}$ Complexo hospitalar Regional de Cacoal (COHREC), Cacoal - RO.

*E-mail: poli_deyse_pereira@hotmail.com

${ }^{2}$ Hospital de Urgência e Emergência Regional de Cacoal (HEURO). Cacoal - RO. 
experiencia: Es a cerca de uma una adolescente, víctima de una quemadura en un accidente que involucra una explosión al encender una parrilla de barbacoa con etanol,tuvo el $49 \%$ de la superficie del cuerpo quemada, fue ingresada en el hospital donde el tratamiento se realizó junto con el equipo multidisciplinario y el fué realizado por las enfermeras residentes durante un período de 40 días, con seguimiento después del alta. Conclusión: Encontró una escasez de estudios sobre el uso de cubiertas para quemaduras, y es necesario capacitar al equipo multidisciplinario, llamando más la atención a las enfermeras que están en primera línea, para brindar el apoyo necesario a los pacientes quemados, dejándolos con mínimas secuelas mentales, sociales y físicas.

Palabras clave: Quemadura, Enfermera, Cicatrización de Heridas.

\section{INTRODUÇÃO}

Cerca de 1,25 milhões de pessoas sofrem algum tipo de queimadura por ano. Em vários países, a queimadura é considerada um problema de saúde pública, sendo a quinta causa de morte acidental no mundo, de acordo com os dados da Organização Mundial de Saúde. Fatores como baixa escolaridade, moradias precárias, habitações superlotadas, além da carência de campanhas de educação pública, contribuem para a ocorrência de queimadura acidental em muitos países, sendo nos Estados Unidos, a quarta maior causa de morte por trauma (TEODORO AL e PAIVA VS, 2013; MARQUES MD, et al., 2014).

As vítimas de queimaduras têm como consequência às cicatrizes, que podem desenvolver eritemas, discromias, hipertrofias e limitações de funcionalidade, necessitando de reavaliações de condutas, e também, podem apresentar necessidades de intervenções como, curativos, enxertos e retalhos (GONÇALVES AC, et al., 2013).

A qualidade da assistência de enfermagem é essencial na recuperação do paciente com grandes queimaduras, cabendo à equipe de enfermagem, fornece apoio físico e emocional, abordando o paciente integralmente, pois são traumas de considerável gravidade, podendo envolver distúrbios metabólicos e fragilidade psicológica. Conhecer a etiologia da queimadura é um fator determinante para direcionar esse apoio (CHAGAS DC, et al., 2015).

Há poucos estudos no Brasil que abordam o levantamento de dados epidemiológicos sobre este tema, além disso, existe a necessidade de apresentar a realidade destes pacientes, já que não há um banco de dados nacional, bem como alertar as autoridades, em especial as sanitárias, sobre a prevenção de acidentes envolvendo queimaduras e as consequências desta situação (CRUZ BF, et al., 2012).

Durante a vivência na residência nos deparamos com diversas situações de pacientes com grande queimado, e observamos que, em sua maioria, os profissionais atuantes neste local não tinham conhecimento sobre o que fazer e como agir, devido à falta de protocolos implantados que dificulta 0 atendimento padronizado e a falta de qualificação adequada da equipe multiprofissional atuante neste serviço. Diante do exposto o objetivo da pesquisa foi relatar o caso de um paciente vítima de queimadura, caracterizando a evolução das feridas, relatando sobre as coberturas utilizadas durante todo o tratamento.

\section{DETALHAMENTO DO CASO}

O referente estudo foi realizado com base em revisão de prontuário de uma paciente admitida na clínica cirúrgica de um hospital de urgência e emergência do interior de Rondônia, vítima de grande queimadura. A pesquisa foi realizada após aprovação do Comitê de Ética e Pesquisa (CEP), via Plataforma Brasil, com o número CAAE: 10402919.9.0000.5298, parecer no 3.349.692. Foi entregue a participante um termo de consentimento livre e esclarecido (TCLE), devido às imagens das feridas, que foram realizadas para acompanhamento clinico e que serão expostas nesse trabalho.

A Paciente A.C.S.R., 18 anos, sexo feminino, parda, peso $52 \mathrm{~kg}$, estudante do ensino fundamental, procurou atendimento de urgência no Hospital de Urgência e Emergência Regional de Cacoal/RO 
(HEURO), no dia 11 de dezembro de 2018, após sofrer queimaduras em um acidente envolvendo uma explosão ao acender uma churrasqueira com etanol. Ao chegar foi avaliado vias aéreas, sendo a mesma integra e ressuscitação hídrica com Soro Fisiológico (SF) 0,9\% 4000M ml em 8h e após $3500 \mathrm{ml}$ em 16h, dose de ataque de antibioticoterapia com ceftriaxona $\AA_{2}$ gr,curativo estéril com cobertura de sulfadiazina de prata $\AA$, e Sondagem vesical dedemora para controle de balanço hídrico, foi admitida na sala vermelha do hospital para observação de 24h.

Ao exame físico, foi constatada aproximadamente $49 \%$ da superfície corporal queimada (SCQ),calculada pela regra dos noves Wallace, com queimaduras de $1^{\circ}$ e $2^{\circ}$ grau nas regiões de face $(4,5 \%)$, tórax anterior(18\%),Membros superiores (MMSS) (9\%),Membros inferiores (MMII) (18\%)e região glútea. Paciente não apresentou nenhuma instabilidade hemodinâmica e no dia seguinte foi transferida para clínica cirúrgica do hospital em isolamento de contato protetor.

A figura abaixo está relacionada ao segundo dia de internação da paciente, com a troca de curativo, sendo utilizado novamente a Sulfadiazina de prata $\AA$. Ainda apresentavam-se bastantes bolhas íntegras, na qual escolhemos não rompê-las.

Figura 1 - Segundo dia de internação da paciente, troca do curativo com aplicação novamente de Sulfadiazina de prata®, 2018.

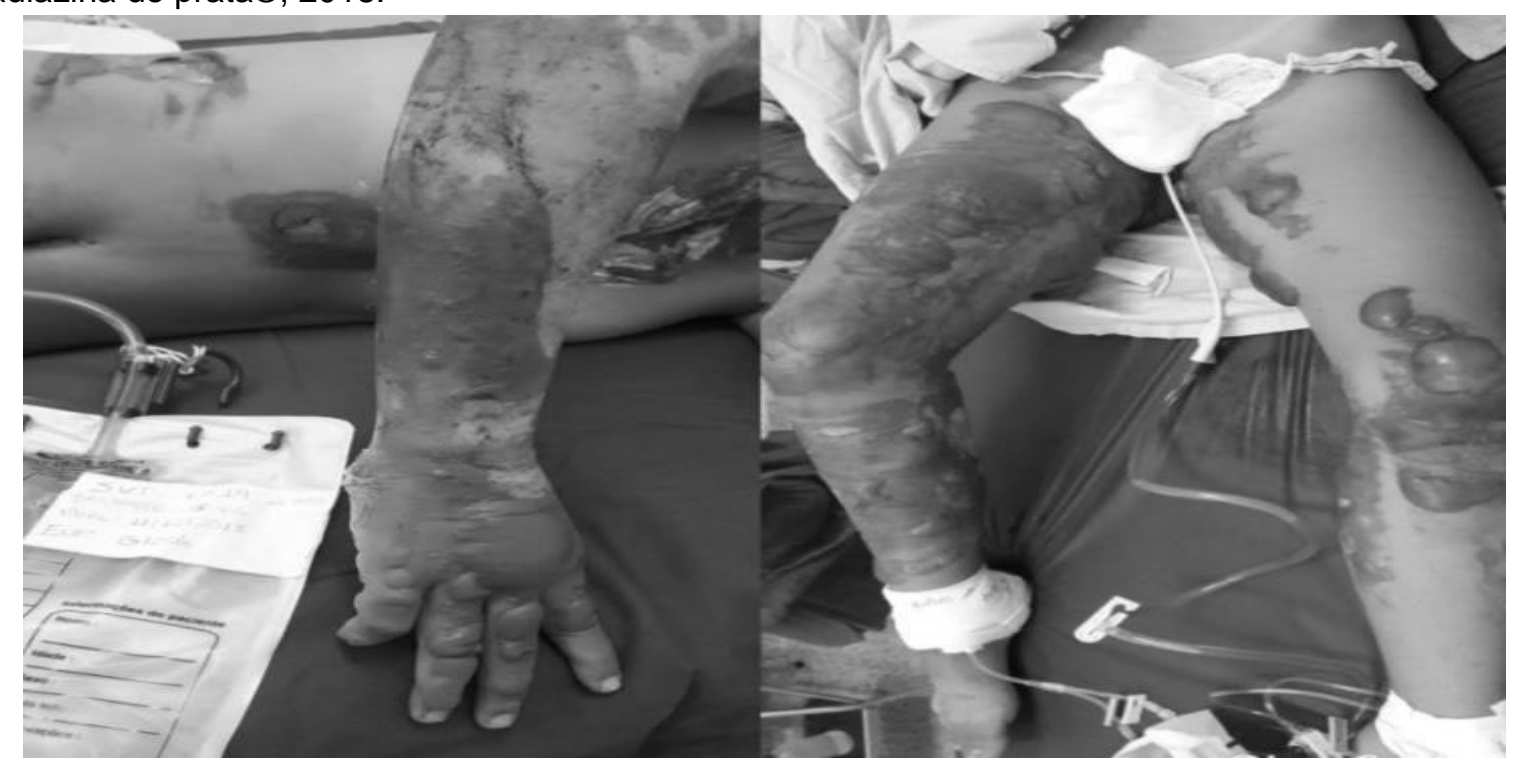

Fonte: Gouvêa PDP, et al., 2019.

Na clínica foi realizado a continuidade do tratamento juntamente com a equipe multidisciplinar e a realização dos curativos pelas Enfermeiras residentes do primeiro programa multiprofissional em atenção hospitalar/urgência e trauma, com um preceptor que acompanhou todo o processo, durante um período de 40 dias.

Durante o tratamento utilizamos também ○ Hidrogel, Purilon® Gel, promovendo o desbridamento autolítico em crostas de necrose de liquefação que se formaram. Observamos que sua eficiência requer um tempo prolongando de utilização, para que a ação do produto seja completa, tivemos dificuldade em aplicar ele sobre o leito da ferida, pois, por ter uma composição mais consistente necessitava de uma maior fricção, o que causava dor na paciente. Outra dificuldade que encontramos foi na retirada do produto de seu frasco que é tipo sanfona, o final da bisnaga era bem resistente e se perdia muito produto por não conseguir efetuar a total retirada.

A figura abaixo está relacionada ao sétimo dia de internação da paciente, com a troca de curativo, onde foi utilizado o Hidrogel Purilon® Gel para o desbridamento, a ferida apresentando muito tecido de necrose de liquefação pós desbridamento do tecido desvitalizado inicial. 
Figura 2 - Sétimo dia de internação da paciente, formação de necrose de liquefação pós desbridamento de todo o tecido desvitalizado inicial, 2018.

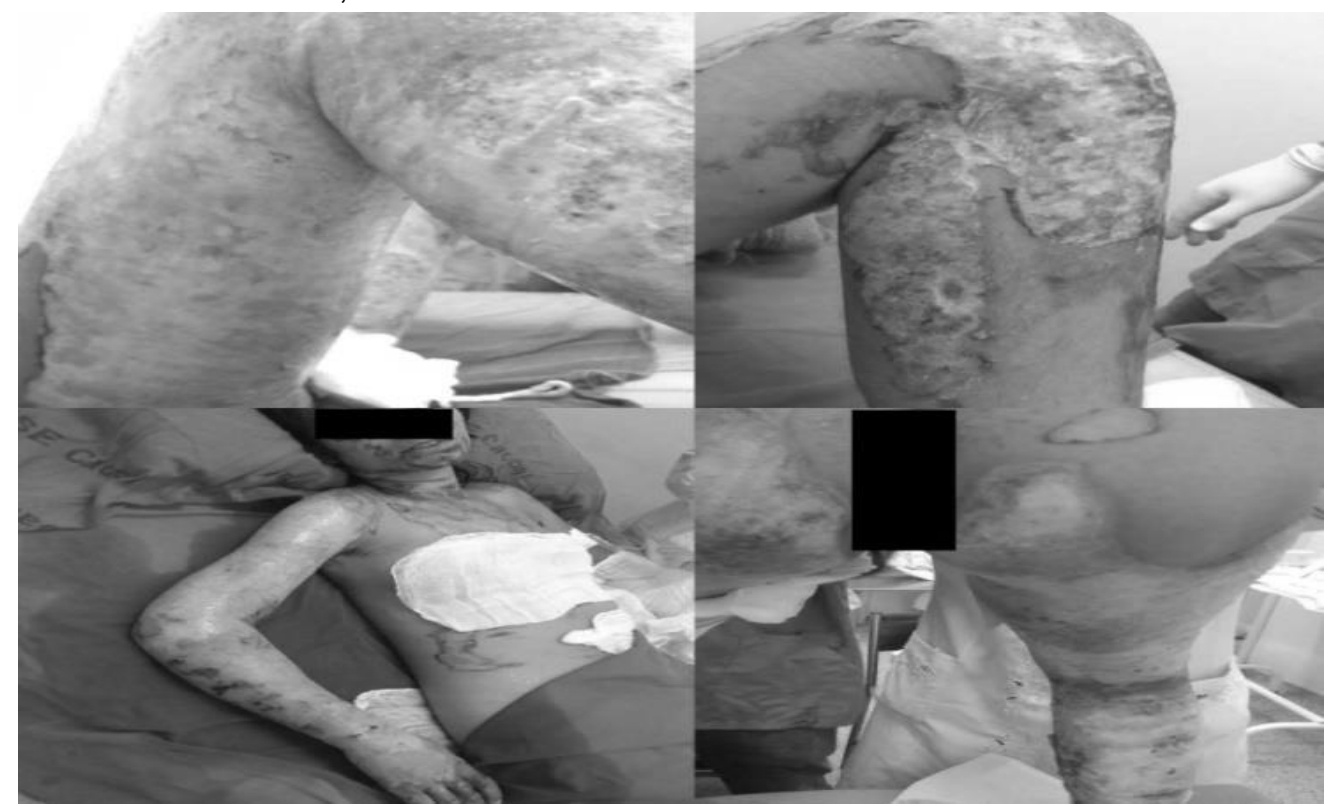

Fonte: Gouvêa PDP, et al., 2019.

A figura três está relacionada ao vigésimo quarto dia de internação da paciente, onde a ferida apresentou vários pontos hemorrágicos e foi utilizado a placa de alginato de cálcio juntamente com o Hidrogel Purilon $\circledast$ Gel para o desbridamento e hemostasia do sangramento, além de apresentar pontos de epitelização.

Figura 3 - Vigésimo quarto dia de internação da paciente, ferida apresentando pontos hemorrágicos, 2018.

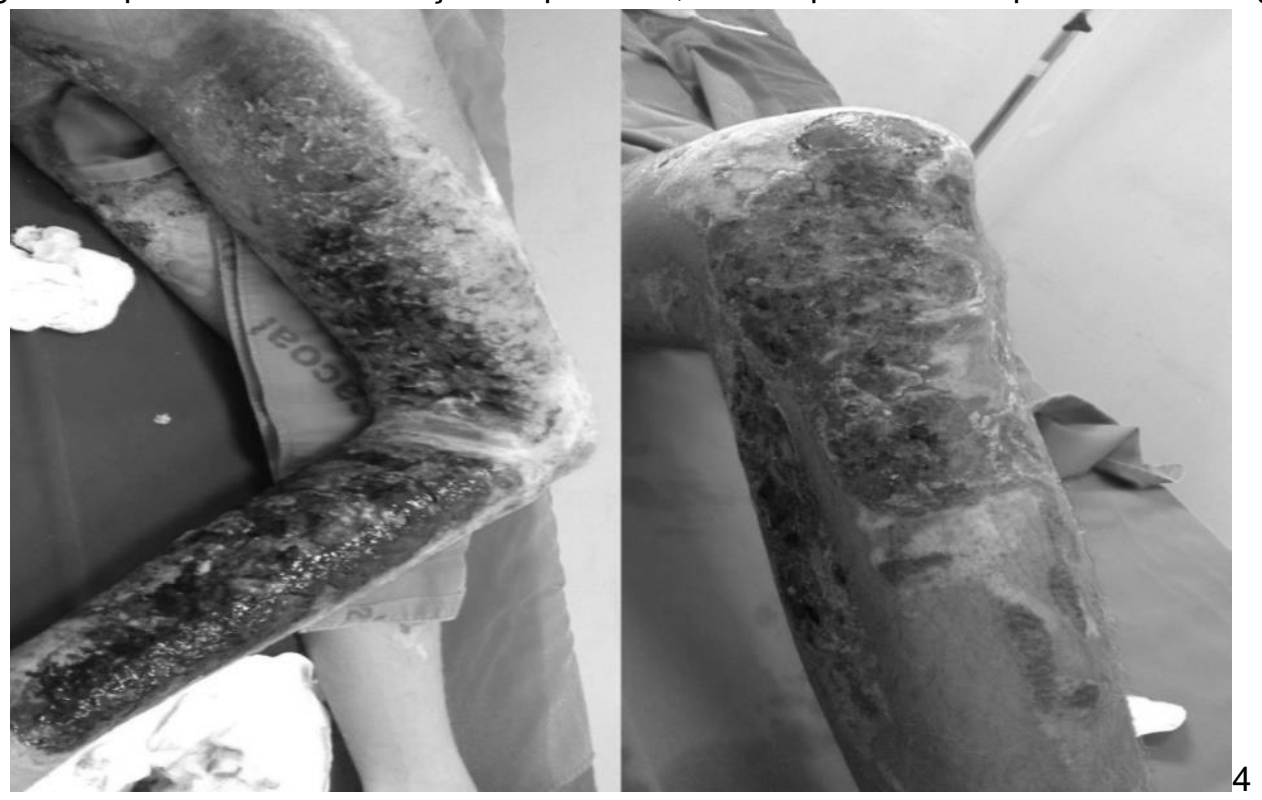

Fonte: Gouvêa PDP, et al., 2019.

Durante todo o tratamento utilizamos Adaptic $®$ Malha Não Aderente, onde os resultados foram excelentes, acelerando o processo de cicatrização, fácil remoção, não ocasiona dor e nem desconforto durante sua aplicação. Segundo informações do fabricante, é uma compressa primária não-aderente de acetato de celulose levemente impregnada com uma emulsão a base de petrolato. Assim, ela previne a 
aderência ao leito da ferida, protegendo o tecido de granulação, permite uma remoção sem causar trauma nem dor, previne a retenção de fluidos no leito da ferida, reduzindo a maceração e pode permanecer vários dias na ferida, dependendo da quantidade de exsudado.

A figura quatro está relacionada ao vigésimo sétimo dia de internação da paciente, onde foi realizado a troca de curativo feito na imagem anterior, onde houve melhora significativa do aspecto da lesão e controle do sangramento, e mantivemos a cobertura de Hidrogel Purilon® Gel + Adaptic ${ }^{\circledR}$ Malha Não Aderente.

Figura 4 - Vigésimo sétimo dia de internação da paciente, após utilização da placa de alginato de cálcio juntamente com o purilon, 2018.

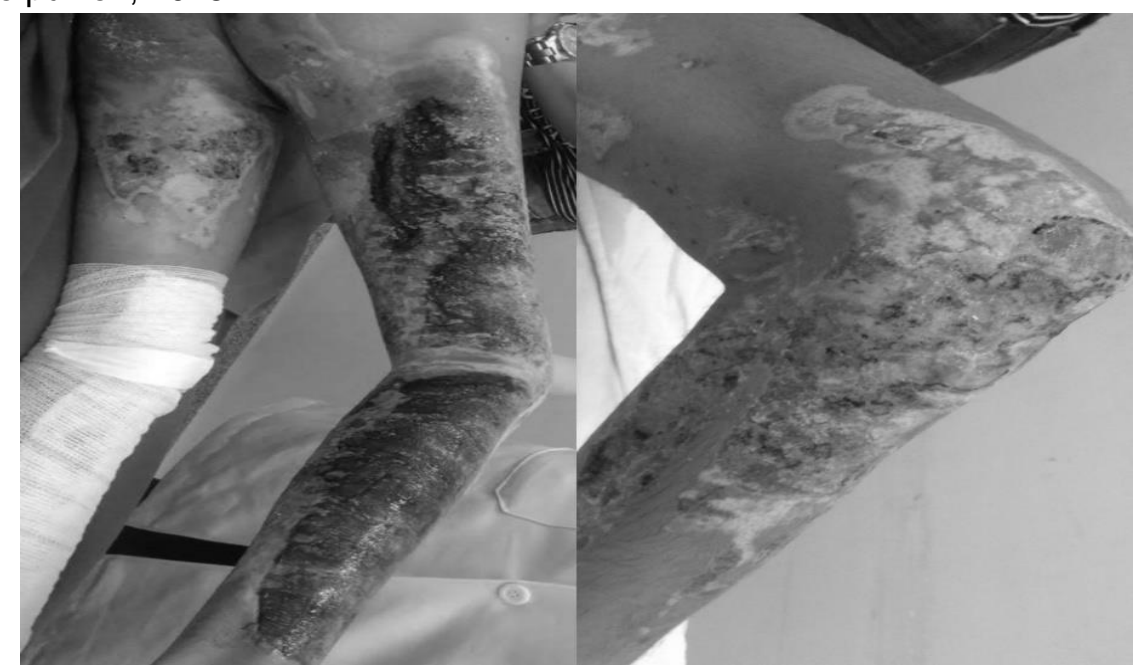

Fonte: Gouvêa PDP, et al., 2019.

A paciente teve alta com orientações realizadas pelas enfermeiras e prosseguiu com acompanhamento das mesmas juntamente com equipe da UBS em sua residência. Infelizmente, após alta, a ferida regrediu na cicatrização, hipergranulou e apresentou sinais de infecção, a paciente não seguiu orientações de se movimentar e o membro inferior direito apresentou contratura cicatricial, impedindo assim o movimento completo de extensão do membro, sendo necessária intervenção da cirurgia plástica. Somente após08 meses da alta a ferida cicatrizou completamente.

A figura abaixo está relacionada aos curativos domiciliar, apresentando a hipergranulação e sua evolução após o tratamento com a placa de alginato de cálcio com compressão das ataduras.

Figura 5 - Paciente em seu domicilio, evolução da ferida após tratamento de hipergranulção, 2018.

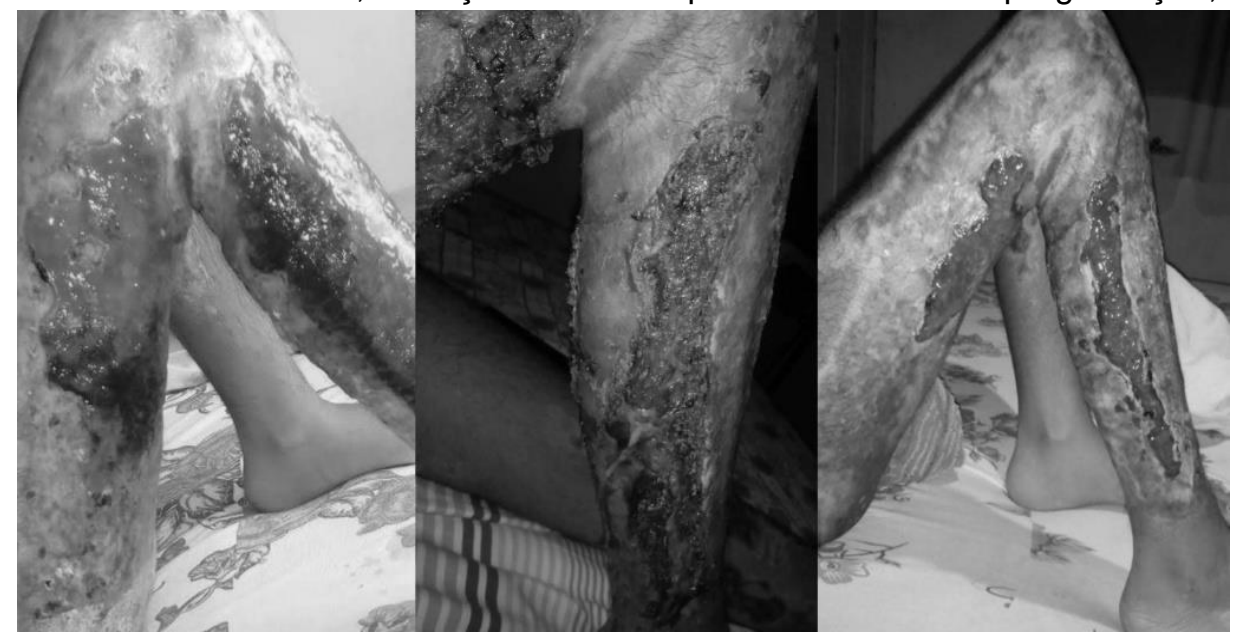

Fonte: Gouvêa PDP, et al., 2019. 
De acordo com o relato de caso apresentado acima, os dados apresentados a seguir retratam todo o tratamento hospitalar e evolução da paciente.

Tabela 1 - Tratamento das feridas realizado de acordo com a evolução clínica de uma paciente vítima de grande queimado no ambiente Hospitalar.

\begin{tabular}{|c|c|c|}
\hline Dias & Coberturas utilizadas & $\begin{array}{c}\text { Desbridamento } \\
\text { Mecânico }\end{array}$ \\
\hline 10 & Sulfadiazina de prata & \\
\hline $2^{0}$ & Sulfadiazina de prata & $\mathrm{X}$ \\
\hline $3^{\circ}$ & Adaptic ${ }^{\circledR}$ Malha Não Aderente + Aquacel® Ag + Óleo AGE & $\mathrm{X}$ \\
\hline $4^{\circ}$ & mantido curativo & \\
\hline $5^{\circ}$ & Sulfadiazina de prata + Óleo AGE & \\
\hline $6^{\circ}$ & Sulfadiazina de prata + Óleo AGE & \\
\hline $7^{0}$ & Purilon $\circledast$ Gel + Adaptic $\circledast$ Malha Não Aderente + Aquacel$\circledast \mathrm{Ag}$ & $\mathrm{X}$ \\
\hline $8^{\circ}$ & mantido curativo & \\
\hline 9은 & Óleo AGE + Purilon $\AA$ Gel + Aquacel ${ }^{\circledR}$ Ag + Saf-gel ${ }^{\circledR}$ & $\mathrm{X}$ \\
\hline $10^{\circ}$ & $\begin{array}{c}\text { MMII: Adaptic® Malha Não Aderente + Purilon® Gel +Aquacel® Ag } \\
+ \text { +Biatain® AG não adesivo + Creme barreira }\end{array}$ & $\mathrm{X}$ \\
\hline $11^{0}$ & mantido curativo & \\
\hline $12^{0}$ & mantido curativo & \\
\hline $13^{\circ}$ & mantido curativo & \\
\hline $14^{\circ}$ & $\begin{array}{c}\text { Óleo AGE+Adaptic } \AA \text { Malha Não Aderente + Purilon } \AA \text { Gel } \\
\text { +Aquacel® Extra }\end{array}$ & $\mathrm{X}$ \\
\hline $15^{0}$ & mantido curativo & \\
\hline $16^{\circ}$ & mantido curativo & \\
\hline $17^{0}$ & Saf-gel® + Óleo AGE & $\mathrm{X}$ \\
\hline $18^{\circ}$ & mantido curativo & \\
\hline $19^{\circ}$ & mantido curativo & \\
\hline $20^{\circ}$ & MID: Saf-gel $\AA$ + Óleo AGE & \\
\hline $21^{\circ}$ & $\begin{array}{l}\text { Óleo AGE+Adaptic® Malha Não Aderente + Saf-gel@ + Aquacel® } \\
\text { Extra }\end{array}$ & $\mathrm{X}$ \\
\hline $22^{0}$ & mantido curativo & \\
\hline $23^{\circ}$ & mantido curativo & \\
\hline $24^{\circ}$ & $\begin{array}{l}\text { Óleo AGE+Adaptic® Malha Não Aderente + Purilon® Gel + Placa } \\
\text { Alginato de cálcio }\end{array}$ & $\mathrm{x}$ \\
\hline $25^{\circ}$ & mantido curativo & \\
\hline $26^{\circ}$ & mantido curativo & \\
\hline $27^{\circ}$ & Óleo AGE+Adaptic $\AA^{\circledR}$ Malha Não Aderente + Purilon $\circledast$ Gel & $\mathrm{X}$ \\
\hline $28^{\circ}$ & Óleo AGE+Adaptic $\AA^{\circledR}$ Malha Não Aderente + Purilon $\circledast$ Gel & $\mathrm{X}$ \\
\hline $29^{\circ}$ & mantido curativo & \\
\hline $30^{\circ}$ & Troca da cobertura secundaria & \\
\hline 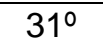 & Troca da cobertura secundaria & \\
\hline $32^{\circ}$ & Óleo AGE+Adaptic® Malha Não Aderente & \\
\hline $33^{\circ}$ & mantido curativo & \\
\hline $34^{\circ}$ & mantido curativo & \\
\hline $35^{\circ}$ & Óleo AGE+Adaptic® Malha Não Aderente & \\
\hline $36^{\circ}$ & mantido curativo & \\
\hline $37^{\circ}$ & $\begin{array}{l}\text { Óleo AGE+Adaptic® Malha Não Aderente + Saf-gel® + Placa } \\
\text { Alginato de cálcio }\end{array}$ & \\
\hline $38^{\circ}$ & Óleo AGE+Adaptic® Malha Não Aderente & \\
\hline $39^{\circ}$ & Óleo AGE+Adaptic® Malha Não Aderente & \\
\hline ALTA & Óleo AGE+Adaptic® Malha Não Aderente & \\
\hline
\end{tabular}

Legenda: A letra " $X$ " indica os dias que foram realizados o desbridamento mecânico. Fonte: Gouvêa PDP, et al., 2019. 


\section{DISCUSSÃO}

No tratamento inicial de queimaduras de segundo e terceiro grau um curativo bastante recomendado, devido seu efeito antimicrobiano, é a sulfadiazina de prata. Porém, a necessidade de trocas diárias devido à oxidação da prata é uma desvantagem dessa cobertura (OLIVEIRA BGRB, et al.,2011). Essas coberturas com prata têm sido alvo de constantes estudos devido sua capacidade antimicrobiana, e inúmeras pesquisas científicas demonstram certa eficácia na utilização desses curativos para tratamento de feridas, destacando a sua importante função na cicatrização e seu efeito bactericida, que auxilia para uma melhor reepitelização (MOSER H, et al., 2013; TAVARES WDS e DA SILVA RS, 2015).

No caso da paciente em questão, como primeira escolha de cobertura foi utilizado a Sulfadiazina de prata com troca a cada $24 \mathrm{~h}$ nos primeiros dois dias de internação. Na prática, encontramos dificuldades na remoção da cobertura, devido ela aderir ao leito da ferida onde, em alguns lugares tivemos que fazer forte friç̧ão para retirá-la e em outros nem conseguimos, devido à dor que a paciente sentia, mesmo após analgesia preventiva.

Após utilização da Sulfadiazina de prata demos continuidade ao tratamento com a cobertura Aquacel $\AA \mathrm{Ag}+$, assim, garantimos o efeito bactericida da prata e minimizamos a quantidade de exsudato pós desbridamento mecânico. Obtivemos um bom resultado com essa cobertura, pois ela não adere ao leito da ferida, sendo de fácil remoção, absorve bem o exsudato, além, de não precisar realizar a troca diária garantindo menor tempo de cicatrização, tempo de trabalho de enfermagem e maior conforto na hora da troca de curativo. Após os 13 dias de utilização do Aquacel $\AA^{A} \mathrm{Ag}+$, passamos utilizar quando era necessário a placa de Aquacel Extra ${ }^{\circledR}$, que tem as mesma indicações e benefícios, exceto o efeito antimicrobiano da prata.

Devido à falta de alguns produtos na instituição tivemos que substituir algumas coberturas no meio do tratamento, porém as trocas eram sempre realizadas por uma com ações parecida à antiga. Devido a pouca quantidade de Aquacel® Ag+ em um dos curativos substituímos pelo o Biatain® Ag não adesivo, porém tais coberturas possuem como sua principal indicação ferida muito exudativas pela capacidade de reterem umidade e tem importante atividade antimicrobiana, dessa forma provam ser eficazes no manejo de queimaduras já que promovem um ambiente propício para a cicatrização da ferida sem lesar os tecidos em regeneração (MARKS G, 2013).

Existem poucos estudos que relacionam a utilização do Purilon® Gel com pacientes queimados, apesar de ser uma de suas indicações para uso e de seus benefícios, que pode ser usado em várias fases da cicatrização, não danifica o tecido de granulação e promove alívio e conforto (MANDELBAUM SH, et al., 2003). Os hidrogéis são utilizados no tratamento de feridas cutâneas, pois promove um ambiente úmido na superfície da ferida por liberação de água, fato que favorece o processo de cicatrização (LOO Y, et al., 2014).

Outro Hidrogel que utilizamos e que é pouco citada na literatura em relação a curativos em pacientes queimados é o Saf-gel® que é um Hidratante com Alginato de Cálcio e Sódio, tendo como indicação ferida secas e com necrose, devida sua ação de desbridamento autolítico seletivo, tendo com uma das funções também ser hemostático para feridas sangrantes devido o alginato, além da troca se dar em até sete dias conforme exsudação, como explica a bula do fabricante.

Obtivemos excelentes resultados com a sua utilização, a evolução da ferida era significante, pois a troca de curativos era com menor frequência, é de fácil manejo, além de poder ser utilizado em todos os tipos de tecido, pois o mesmo não agride o tecido de granulação, umedecendo e facilitando a retirada das necroses no desbridamento mecânico. O único ponto negativo de sua utilização era que a paciente relatava sensação de estar "pegando fogo" no local da aplicação e só melhorava após oclusão com cobertura secundária úmida.

Além do Saf-gel $\AA^{\circledR}$ que contém o Alginato de Cálcio, foi necessário utilizar a placa de Alginato, devido à paciente ter apresentado vários pontos hemorrágicos no leito da ferida, causando grande quantidade de exsudato, assim, tivemos ótimos resultados com sua ação de absorção, o ponto negativo é que a paciente relatava uma sensação de como se tivesse perfurando-a, acreditamos que devido à placa ter um aspecto áspero e o leito da ferida estar sensível, pois não encontramos nenhum outro relato sobre esse aspecto. 
Essa cobertura tem sido aplicada com sucesso para limpar uma ampla variedade de lesões secretivas, com exsudato de moderado a intenso. É altamente absorvente, mantém um microambiente fisiologicamente úmido o que permite a troca gasosa e provê uma barreira para a contaminação, além de promover a cicatrização e a formação de tecido de granulação (JONES V, et al., 2006).

Entre as inúmeras opções de tratamento para queimaduras, é recomendada a utilização dos os Ácidos Graxos Essenciais (AGE), pois a capacidade de modificar reações inflamatórias e imunológicas, alterando funções leucocitárias e acelerando o processo de granulação tecidual, podendo ser usado diretamente sobre o leito da ferida ou embebidos em gases estéreis, com desvantagem de trocas com no máximo 24 horas (TIMÓTEO AP, 2014).

O uso de AGE no tratamento de feridas é amplamente utilizado no Brasil, porém encontraram-se poucos estudos sobre sua utilização. É necessário realizar mais pesquisas clínicas nesta área e para a Enfermagem estes achados representam um alerta para a necessidade da prática baseada em evidência (MANHEZI AC, et al., 2008).

No decorrer do tratamento hospitalar e após alta da paciente utilizamos AGE, porém foi observado que devido seu uso continuo ocorreu uma ação adversa que foi a hipergranulação da ferida, como ele atua no processo de cicatrização, aumentando a permeabilidade celular estimulando sua proliferação, seu uso prolongado pode causar a hipergranulação, e um dos tratamentos escolhidos para resolução desse problema foi a placa de alginato de cálcio com compressão das ataduras, o que resultou na melhora.

Encontramos alguns questionamentos, ainda sem resposta ou com controvérsias, na literatura sobre o tratamento das queimaduras. Alguns autores mencionam a deficiência de informações específicas sobre as indicações e efeitos adversos dos produtos mais utilizados em queimaduras. Os profissionais de saúde têm se sentindo inseguros sobre qual opção é mais indicado para o tratamento de queimaduras, tendo em vista a gama de produtos que o mercado está oferecendo, com isso, é preciso conhecer a eficiência de cada produto frente à diversidade de situações. Vale ponderar que, o sucesso do tratamento depende, dentre outros fatores, da criteriosa escolha, bem como, da adequada utilização dos produtos selecionados (TIMÓTEO AP, 2014).

O cuidado de enfermagem realizado em hospital visa recuperar o tecido lesado para redução da dor, satisfação do paciente, tempo de cura diminuído e prevenção de sequelas, e que é no domicílio que se restabelece a funcionalidade, com a diminuição das sequelas físicas e motoras ocasionadas pela lesão (SANTANA CML, et al., 2012).

Através desse estudo, pode-se perceber que há uma grande variedade de coberturas disponíveis no mercado, e que a busca por melhorias na tecnologia e avanços no desenvolvimento de novas coberturas para queimadura estão crescendo. Todavia, constatou uma escassez de estudos sobre o uso de coberturas em queimaduras, onde houve dificuldades em correlacionar as evidências da pratica com a teoria. $O$ objetivo proposto neste trabalho foi atingindo ao relatar o caso da paciente vítima de grande queimado, com ênfase maior no curativo e suas coberturas, mostrando que, apesar das intercorrências ocorridas após a alta, é possível a obtenção de sucesso no tratamento de casos graves de queimaduras fora de um centro especializado em queimaduras graves.

\section{REFERÊNCIAS}

1. CHAGAS DC, et al., Assistência de enfermagem ao paciente com grandes queimaduras. Revista Interdisciplinar. 2015; 7(4): 50-60.

2. CRUZ BF, et al. Perfil epidemiológico de pacientes que sofreram queimaduras no Brasil: revisão de literatura. Rev. Bras. Queimaduras. 2012;11(4): 246-50.

3. GONÇALVES AC, et al. Avaliação de diferentes áreas de cicatriz na vítima de queimadura pela utilização do Cutometer: relato de um caso. Rev. Bras. Queimaduras. 2013; 12(4): 289-92.

4. JONES V, et al. ABC of wound healing: wound dressings. BMJ: British Medical Journal. 2006; 332(7544): 777.

5. LOO Y, et al. Ultrashort peptide nanofibrous hydrogels for the acceleration of healing of burn wounds. Biomaterials. 2014 ; 35(17): 4805-4814. 
6. MANDELBAUM SH, et al. Cicatrização: conceitos atuais e recursos auxiliares-Parte II. Cicatrization: current concepts and auxiliary resources-Part II. An Bras Dermatol., 5003; 78(5): 525-542.

7. MANHEZI AC, et al. La utilización de ácidos grasos esenciales en el tratamiento de heridas. Revista Brasileira de enfermagem. 2008; 61(5): 620-628.

8. MARK SG. Tratamento da lesão de queimaduras de espessura parcial: revisão integrativa. Universidade Federal do Rio Grande do Sul. Escola de Enfermagem. Porto Alegre. 2016. Disponível em: https://lume.ufrgs.br/bitstream/handle/10183/174311/001061785.pdf?sequence=1\&isAllowed=y

9. MARQUES MD, et al. Perfil epidemiológico dos pacientes grandes queimados admitidos em um hospital de trauma. Rev. Bras. Queimaduras. 2014; 13(4): 232-5.

10. MOSER H, et al. Evolução dos curativos de prata no tratamento de queimaduras de espessura parcial. Rev. Bras. Queimaduras. 2013; 12(2): 60-7.

11. OLIVEIRA BGRB, et al. Atualidades em curativos de grandes queimados. In: Malagutti W, Kakihara CT, orgs. Curativos, estomias e dermatologia: uma abordagem multiprofissional. São Paulo: Martinari; 2011; 549-59.

12. SANTANA CML, et al. Importância da fisioterapia na reabilitação do paciente queimado. Rev. Bras. Queimaduras. 2012; 11(4): 240-5.

13. TAVARES WDS e da SILVA RS. Curativos utilizados no tratamento de queimaduras: uma revisão integrativa. Rev. Bras. Queimaduras. 2015; 14(4): 300-6.

14. TEODORO AL e PAIVA VS. Perfil epidemiológico de pacientes queimados admitidos em um serviço terciário de Caxias do Sul - RS. Rev. Bras. Queimaduras. 2013; 12(2): 108-11.

15. TIMÓTEO AP. A importância do enfermeiro frente ao cuidado e curativo de pacientes queimados. São Paulo, 2014. Disponível em: https:/www.ccih.med.br/wp-content/uploads/2015/04/ana-paula-tim\%C3\%B3teo.pdf. 